\title{
Happiness" as Constructs of Reality for Selected Fourth Year Students of the University of the Philippines Baguio
}

\author{
Yves Peter Carlo de Rivera Medina, ${ }^{1, *}$ \\ ${ }^{1}$ University of the Philippines Baguio, Governor-Pack Road Baguio City 2600, Philippines
}

\begin{abstract}
This paper examined how social media such as the Instagram, provides an avenue for individuals to construct their world as they deem fit and modify it based on subjective truths. Utilizing the method of textual analysis, this paper examined the photographs posted in individual Instagram accounts by selected students of the University of the Philippines Baguio. What appears to be real for them, in this curated form of diary, is that their constructed world is "happy." This paper then addressed these questions: What is their perspective of reality as communicated by the selected Instagram users? How is this depicted in their Instagram accounts? The researcher then has found out that reality in the net space particularly in Instagram is always changing, incoherent, and in determinant.
\end{abstract}

\section{Introduction}

In this day and age, social media has already been part of everyone's daily routine. The emergence of social networking sites gave people an extended platform to express, interact, and share experiences with other people all over the world. One of the rising social media platforms utilized by the younger generation is the Instagram, a photograph social application designed for smartphone that allow its users to share daily experiences through uploading photos to their individual and personalized accounts. This phenomenon sparked the interest of the author to identify and describe the constructs of reality of selected Instagram users. As Poster stressed that "the individual becomes aware of participating in something greater than him/herself, something where the individual does not have a fixed vantage point [1]". In his book entitled "Mode of Information," Poster wrote that in the presence of the net space "the self is decentered, dispersed, and multiplied in continuous instability [2]". Taking off from Poster's statement then, the net space, specifically in the use of social media such as the Instagram, provides an avenue for individuals to construct their world as they deem fit and modify it based on subjective truths. This study then, utilized textual analysis and examined the photographs posted in individual Instagram accounts by selected fourth year students of the University of the Philippines Baguio. Presenting a curated form of diary, Instagram accounts compiled and read in this research, narrates on the Instagram users' constructed notions of reality.

\footnotetext{
*Corresponding author: ypcmedina@gmail.com/nehemiahbangalan@gmail.com
} 


\subsection{The Problem}

Reading the Instagram accounts of selected fourth year students of the University of the Philippines Baguio, the study examined the constructed notions of reality by reading the bevy of photographs posted and uploaded in their individual profile accounts. Addressing these two questions: 1) What is their perspective of reality as communicated by the selected Instagram users? and, 2) How is this depicted in their Instagram accounts? Upon answering these questions, the researcher presented the perceived reality of the Instagram users by attempting to explain how their reality becomes incoherent and indeterminant.

This study used Mark Poster's The Mode of Information as a theoretical underpinning in the reading of constructs of reality in the online space. Coining the term mode of information, Poster proposes three general stages of the mode of information that corresponds to the manner in which messages are communicated. These stages are, face-toface, print age, and lastly the electronic mediated stage [3]. This paper, however, gave focus on the electronic mediated stage. Poster posits that communication in the electronic age is instantaneous and is not restricted by time and space [4]. With the existence of electronically mediated communication, communication as a field now can be described as the transfer of information across space and time. It usually comes in representation of the language. It can be a symbol, text, and/or images. Communication plays vital role in the construction of reality. It is important to note that reality is made through messages sent by an individual. In the case of Poster's electronic age, the constructs of reality are established through the representation of language an individual post in an electronic medium. These representations convey meaning and shape the constructs of reality.

\section{Reality as Depicted by Photographs in the Instagram Accounts}

In determining the constructs of reality, the researcher has identified twenty-two emerging themes from the photos of the respondents. This table illustrates the number of photos per theme, the frequency of the appearances of these themes to the respondents and their corresponding ranks according to frequency. From this table, the top five emerging themes are identified. The top emerging themes were: a) Selfie and Self Portraits, b) Groupfies and Friends c) Food and Drinks d) Nature e) Academics. Two salient subject photographs were also on: a) feet and b) motivational and inspirational quotes. From these constructs then, the researcher established the notions of reality of the respondents.

Table 1. Frequency, Percentage and Ranking of Themes

\begin{tabular}{|l|c|c|c|c|}
\hline \multicolumn{1}{|c|}{ Themes } & No. of Photos & $\begin{array}{c}\text { Appearances } \\
\text { in the Profile } \\
\text { of 30 } \\
\text { Respondents }\end{array}$ & $\begin{array}{c}\text { Percentage } \\
\text { Based on } \\
\text { Appearances }\end{array}$ & $\begin{array}{c}\text { Rank Based } \\
\text { on the No. of } \\
\text { Appearance in } \\
\text { the 30 } \\
\text { Respondents }\end{array}$ \\
\hline Selfie and Self Portraits & 282 & $27 / 30$ & $90 \%$ & 1 \\
\hline Groupfies and Friends & 226 & $24 / 30$ & $80 \%$ & 2 \\
\hline Food and Drinks & 252 & $23 / 30$ & $76.76 \%$ & 3 \\
\hline Nature & 139 & $22 / 30$ & $73.33 \%$ & 4 \\
\hline Academics & 118 & $21 / 30$ & $70 \%$ & 5 \\
\hline Random Objects & 112 & $21 / 30$ & & 6 \\
\hline Others & 86 & $20 / 30$ & $66.67 \%$ & 7 \\
\hline Quotes & 55 & $18 / 30$ & $60 \%$ & 8 \\
\hline Book & 21 & $17 / 30$ & $56.67 \%$ & \\
\hline
\end{tabular}




\begin{tabular}{|l|c|c|c|c|}
\hline Family & 72 & $16 / 30$ & $53.33 \%$ & 9 \\
\hline Artwork & 41 & $15 / 30$ & $50 \%$ & 10 \\
\cline { 1 - 3 } Feetfie & 32 & $15 / 30$ & & \\
\hline
\end{tabular}

\subsection{Constructed Reality in Instagram}

Reality is everything that an individual considers to be real. And in Instagram, the respondents have set a certain kind of reality by posting different photos of self, friends, food and drinks, nature, academics, feet and quotes.

Selfie and Self Portraits. In this theme, respondents represent their self-image in varied ways but there are common traits that can be traced in each photo. The respondents wish to create a self-image in Instagram which is free from weakness, failures, and sadness. Moreover, it is important to note that, since this is the top theme, respondents find their self- image as the utmost priority. They put primacy to their self -image. This reflects the priorities of the youth today. Furthermore, the projection of their lives as happy and positive attempts to convince the online community that they are living a perfect life in a perfect world. They choose not to expose their weakness and that they are living their lives with full of comforts. In doing so, they somehow internalize this behavior in their real lives and actually believe that they have this kind of life.

Groupfies and Friends. "Tell me who your friends are, and I will tell you who you are" still holds true today. By posting online who your circle of friends is, is like telling the people what kind of person you are. Moreover, the manner in how the respondents present their friends also depicts a positive and happy life. This is regardless of the context of the photos. Respondents frame everything in a positive angle including moments under pressure and stress. This affirms that respondents see Instagram as platform to share only happy moments. Lastly, this theme placed second to selfie and self-portraits which shows that aside from their self, friends are the second top priority of the respondents. Aside from themselves, people around them are what make them.

Food and Drinks. Food and drinks' reality in the online world should be anything that is fancy; something that looks expensive. For the respondents, typical meals prepared at home are not the food qualified for Instagram. They have established the notion of only food with good plating is real in the application. Moreover, they stressed that these good foods actually serve as their comfort and source of happiness in times of stress.

Nature. In this theme, respondents view nature as something that is directly connected to their personal lives. They do not post nature just to give its appearance dignity rather they post nature photos to actually represent anything that can symbolize what they are feeling or thinking.

Academics. Their idea of academics is the real-life application of what are learned in class. They show to people the career that they might be pursuing after college. Furthermore, they also view academics to be stressful but they understand that these are part of the struggles in reaching their dreams.

Feetfie and Quotes. Respondents actually see their feet as good representation of themselves. Their state, fashion and mindset in life can be substituted by their feet in the online world. Furthermore, they Feetfie photos show that they believe that life is a journey. On the other hand, respondents see quotes as pieces of advice they need to hear. They use 
inspirational messages to communicate what they are feeling or what they need. Moreover, they see quotes as something that can uplift not only them but also the people who they share their accounts with.

From the descriptions of constructs of reality, reality for them is anything that is happy and positive. Moreover, respondents post different aspects of their lives in their Instagram accounts; and all of these aspects are used to strengthen their self-construct and identity. They use self- portraits, group pictures, food and drinks, nature, academics, feet, and quotes to establish the reality they want. Furthermore, in presenting these aspects, they tend to frame them as happy and optimistic.

Looking at the age group of the respondents (18 to 21 years old), it is not surprising that their notion of reality is reflected on the photos they post. For them, life is full of happiness, hope, positivity, and adventure. However, these things are not actually real. In life, there is a whole spectrum of emotions and experiences that are not only enjoyable but also unsatisfying. And these were not seen on the feed of the respondents in their Instagram accounts.

The physical reality is composed of all things that one can experience---happiness, sadness, anger, fear and the like. On the other hand, constructs of reality in Instagram are filtered. Daily experiences were captured by the respondents using their smartphones and posted them in their Instagram accounts. The danger here is that, photos posted in the application are just highlights of a moment and/or of an experience which cannot actually narrate the whole experience of the respondents. Moreover, reality in the posted photos are already fabricated- from framing the photo, adding filters, partnering it with captions and choosing which experience only is to post in Instagram. These mentioned additional elements to the photos contribute in bridging the gap between the new shape of reality to that of the tangible reality.

Looking at it from a different light, adding filters and effects on photos, putting captions, and framing the photos are essential in establishing a notion of reality these respondents want to set. These behaviors are tools in achieving that Internet reality they wish to show. And in the case of this study, respondents do such behavior to establish a reality which is full of happiness and positivity.

The construct of reality in the application will tell a lot about the respondents. In this modern age, aside from friends, photos posted on Social Media can define what kind of an individual a person is. Moreover, since the online communities of the respondents are almost the same as their physical community, there will be a blur line when the internet reality is penetrated to the physical reality. The notion of reality constructed in their Instagram accounts could affect, in one way or another, the physical reality of the respondents.

Ultimately, looking at the two salient themes- Feetfie and quotes, reality for them can also be represented by their feet and words. These two are great metaphors to sum up one's life; feet as symbol of a person's being and journey and words as symbol of the individual's philosophy. Indeed, reality is too hard to define and cannot have one definition. It varies from context, culture and even age generation. Yet, it is still important to attempt to determine a certain group's construct and notions of reality in order to understand certain behaviour and know where they are coming from.

\subsection{Mediation of the Image in Reality Construction}

In this study, the physical reality is represented by the photos taken and then posted by the respondents in their Instagram accounts. Today, one way of proving that a certain incident really happened is by taking a picture of it and uploading it in different social networking 
sites, one of which is the Instagram; the interactions are done mostly through posting and exchanging of photos online. Users find this more convenient than actually narrating things through text.

Photos then become the ultimate language of reality in the online space since the users find it more convenient to narrate using photos. Using Poster's posits that a language once represented through the electronically mediated communication, losses its authenticity. It is interesting to see how the physical reality is mediated in Instagram using the selected photos of the users.

While it is true that photos posted by the respondents happened in real life, it is important to look at what kind of scenarios are only posted, how did they frame it and what alterations did they use in enhancing the photos. These behaviors are essential in establishing the subjective reality of the users. From these photos, there emerges the blurry line between the users' notion of reality and truth.

\subsection{Reality as Incoherent}

Incoherency of reality in Instagram is two pronged. One incoherency is observed through the quotes posted by the respondents. They post photos that are inspiring to share and inspire other people. But in reality, they may not be really happy and are currently down so they use inspiring quotes to keep them positive and be reminded that they need to have positive outlook in life.

Second, happiness is the main language of the respondents in their accounts even if the respondents know that their real time and space is not perfect. Their offline space gives them all kinds of experiences, not only happiness. However, the respondents refuse to share these negative and distressing experiences to their online community which makes their reality incoherent.

\subsection{Reality as in determinant}

In this study, it can be observed that the constructs of reality of the respondents are greatly influenced by their environment, particularly their friends. Having a positive and happy life is the reality that is imposed to the respondents. This is why photos posted by the respondents reflect this reality. From their selfie to the quotes that they post, everything depicts the reality as happy and positive. On the other hand, what is also interesting is the theme Feetfie. They actually believe that life is a journey and that they need to keep their feet on the ground.

With these observations, it can be assumed that the reality established in the net space is always changing. In the presentation of photographs of feet which symbolizes direction, goal and being grounded, this sets an articulate language of their reality in the online space; to be and become happy. But, in the real time and space, there are setbacks and hindrances to the path of happiness which they may encounter all the time. To counter-act this real time and space everyday problems, the respondents post quotes to motivate and encourage their own selves. In a way, they continue on in re-constructing their reality as happy in the net space.

Poster said that self-identity and image online is constantly changing. ${ }^{\dagger}$ But, in this case, because the Self is the main topic in the respondents' Instagram accounts, the goal and 
reality aimed for is happiness. Meaning, their self-identity should always be anchored to being and becoming happy.

Indeterminacy of constructed and re-constructed reality in the online space becomes apparent when individuals, in this case, the respondents keep on constructing and reconstructing their goal to become happy only in the online space. Because they can believe they are indeed happy whenever they see their posted photographs but in the offline space they are not. A problem in this arena of indeterminacy poses another challenge. The respondents are determined to be happy in the online space, what if they remain there because the offline space presents reality that is far from their own constructed reality in the online space.

Fragmentation becomes consequential to indeterminacy of the self and constructed reality as two different spaces (online and offline) collide and will not merge. The identity of the respondents may result to multiple identities, i.e., happy in the online space but frustrated in the real world, etc. This fragmentation of identity raises these questions then: Can these respondents re-align themselves and become happy so as to merge the offline and online space realities? Meaning, can they actually control their own happiness in the offline space? If reality in the net space can always be altered depending on the trend in the net space and on what the online community of the users are showing then, what will remain real for these respondents?

As Poster explained, a language once represented through an electronically mediated communication will form new shapes of it; it is the same when the physical reality is represented through photos in Instagram. Photos posted are already filtered by the respondents. They don't usually post everything that happens in their everyday lives. As what the photos collected show, only those that depict happy moments are posted in the Instagram. Moreover, they use filter functions to enhance the aesthetic appeal of the photos. Thus, the researcher poses this question: What do they believe as real?

The selecting, framing, and editing of photos create the reconstructed reality. This reconstructed reality is a reflection of the subjective reality of the users in which they wish to manipulate and shape. From this subjective reality, there is the existence of blurry lines within indeterminacy and incoherency of the users' notion of reality and truth.

It is mentioned earlier that the notion of reality of the users is anything that is happy and positive. This may be true in the online space, but not in the offline space. The offline space provides spaces for failures, problems and negativism. However, users prefer not to show this in the online space. There is no problem with this but with the users' massive subscription to the online space, there might be a consequential creation of a gap in their notions of reality and truth.

Since the online space affords them to create a reality that is more convenient to them, the indeterminacy and incoherency of their truth will arise when the individuals spend more time interacting in their online communities than in their physical ones. An individual may be incoherent with his/her physical and internet reality. When this happens, the quality of relationships of the individual with his/her physical community might be compromised.

\section{Conclusions}

Based on the identified constructs and notions of reality in the respondents' Instagram accounts, Instagram, therefore, is seen as the curated form of diary in the sense that only happy experiences of everyday life are posted. Moreover, unlike the classic diary, Instagram is shared to chosen group. Like any other social media websites, gives its users the power to create one's ideal self; or create multiple versions of self. This phenomenon's role in communication field, however, is until now arguable. Respondents' subscription to the notion of defining a successful life with happy and positive outlook is seen in their 
Instagram accounts. Their notion of reality is a great reflection of the principles and the things they value in life.

Furthermore, apart from the conflict that Internet and Physical reality bring to the lives of the respondents, what is really interesting to discover in this study is the respondents' ultimate pursuit of happiness. Their notion of reality greatly revolves around the idea of becoming and being happy and gaining a positive life. This notion, perhaps, is greatly influenced by the environment of the respondents. Since childhood, a person is always reminded to always follow his/her dreams and to live a happy life. As a person grows, life gets more complicated and again the society reminds him/her that a secret to a successful life is to stay happy and positive. This notion that has been repeatedly imposed to the individuals may have influenced these respondents that regardless of the whole spectrum of emotions and feelings, one prefers to create a reality that is full of happiness and positivity.

From the researcher's observations on the Instagram users' behavior, question now arises, for whom and what are they doing this for? On one hand, it can be assumed that they do this to convince the Instagram community that they actually live this kind of life. On the other hand, this behavior can also be interpreted as the respondents are trying to convince themselves that they actually live this lifestyle, one who has a positive outlook in life and adventurous, by posting it online. It is as if whatever posted in Instagram did really exist in real life or will really exist in real life. In reality, people sometimes complain and get mad and the respondents surely experience these things but these things were not seen in their accounts.

\section{References}

1. Mark Poster. The Mode of Information (Chicago: The University of Chicago Press 2007).

2. S.J. Murray, M. Poster, Qui Parle, 14 (2003)

3. R.E. Babe, E. Comor, Canadian Journal of Cultural Studies, 16 (2006)

4. Poster, Mark. The Mode of Information, (The University of Chicago Press, Chicago, 1990) 